$\xi=$ 不

\title{
Geographical analysis of health facilities in port Harcourt city local government area, rivers state, Nigeria a case study of rivers state, Nigeria
}

\author{
Emmanuel Menegbo * \\ Department of Surveying \& Geo-informatics, Port Harcourt Polytechnic Port Harcourt, Nigeria \\ *Corresponding author E-mail: nenibarini@yahoo.com
}

\begin{abstract}
One of the Millennium Development Goals (MDGs) which 2015 was the target date for its achievement now sustainable goal is stopping the spread of diseases that are preventable. GIS measures coverage, access and pattern's utilization of healthcare services and is important in the research, management, and planning of Healthcare facilities and system. This work, therefore, investigates the spatial distributions of healthcare facilities in Port Harcourt city LGA in Rivers State, Nigeria. Primary data was acquired using GPS handheld receiver and Secondary data such as the attribute (population data, names of hospitals) and spatial data (administrative map, road, and settlement) obtained from government official records. Data obtain shown on a map the spatial distributions of health facilities and access road to the facilities. The result also depicts a spatial distribution's pattern of healthcare facilities and thus insight gain in access to healthcare facilities and services in the LGA.
\end{abstract}

Keywords: GIS; Health Facilities; Port Harcourt City; Spatial Distributions; Accessibility.

\section{Introduction}

The role of good health cannot be overemphasized in the well being and overall development of any society. Accessibility to good health facilities at all levels helps people with health issues to overcome the stress to long distance. Planning and distributions of healthcare facilities using GIS have to gain huge attention all over the world including Nigeria. The United Nations recognized access to medical and basic healthcare services as "the citizen's basic human right." According to Fanan and Felix, (2014), adequate healthcare facilities and effective distributions will contribute to health care provision services and meet the people needs. Mapping Health facilities use Geographic Information Systems technology as the value added information in public health decision making and planning (Abbas et al., 2014). Various kinds of public and private health facilities exist in the city council; however, no spatial information exists listing such facilities.

Shaikh (2013) pointed out that a combination of private and public healthcare facilities are in the urban areas; but, no spatial database in place for such medical facilities. There is geographical maldistribution of urban, rural and regional health care facilities in Nigeria in the past and the present facilities are distributed haphazardly, and the situation can be corrected using reliable data and GIS (Abdurrahman and Nurunnisa, 2013). Port Harcourt city council been an urban area needs more public or private health facilities. For the developing countries, including Nigeria, the doctor/population ratio of 1:10,000 with mean hospital service range of $0-16 \mathrm{~km}$ radius and municipal $1 \mathrm{~km}$ radius have been recommended (Egwu, 1996). These as a result of a combination of factors which include over-population, location, and transportation cost.
This study focused on the spatial distributions of healthcare facilities in Port Harcourt city council city area of Rivers State. The spatial distribution of healthcare facilities in the urban (town) is assessed using Geographic information systems techniques. Furthermore, the healthcare facilities population ratio, and hospital service areas using buffers.

\subsection{The Nigeria health care system}

WHO (2004) defined health care to be services offers to an individual or a community through healthcare providers with the intention of restoring, maintaining and promoting health. WHO (2004) listed healthcare facilities to include; hospitals, isolation camps, primary health-care centre, and burn patient units.

Various levels in healthcare system as outline by WHO (2004) are:

- Intermediate level care: A brief time of intensive treatment and rehabilitation to make patient to go back home after medication or to avoid been taken to a hospital or home care.

- Primary level care: Basic or overall health care with attention on the period at which people normally seeks first help from a healthcare system. This is the reason for referrals forward to next (secondary) or tertiary level of Healthcare.

- Secondary-level care: Specialist healthcare made available for an inpatient level or an ambulatory level, mostly in a referral level from a primary healthcare level.

- Tertiary level care: The availability of a highly level specialized health service in a hospital level and ambulatory settings.

FMH (2009) states the Nigeria Healthcare Bill was established on a National Health System that includes; 
- $\quad$ Federal health ministry

- State health ministry in all states of the federation and Abuja (FCT)

- Health parastatals which is under a federal or state ministry

- Every local government area health department

- All ward level health unit committees

- All village level health unit committees

- All private level health care services providers and

- Traditional \& alternative health care services providers.

Based on the above system, three main level structure of health care operates in Nigeria, that is:

- Federal,

- State, and

- Local governments.

Three categories of health care facilities level also exist in Nigeria. These categories include (FMH 2009);

- primary,

- $\quad$ secondary, and

- Tertiary facilities.

Also, these facilities are owned by Federal, State, and Local governments, and by private individuals or organisations (FMH 2009).

- Primary health care: local level is sole responsibility of local government areas and supported by State health ministry.

- Secondary health care: These services are provided by the State health ministry throughout-patient and in-patient hospital services, which include general medical, surgical, and paediatric cases and community health services. Secondary health care is available at the district, divisional and zone levels of the State. Adequate supportive services, such as laboratory, diagnostics, blood bank, rehabilitation and physiotherapy are also provided.

Tertiary health care: services by State health ministry and the Federal Medical Centre (FMC) and the Specialists Hospital consist of highly specialized services, such as orthopaedic, eye, psychiatric, and paediatric cases. These services are provided by education and at specialist hospitals.

\section{Study area}

Port Harcourt city council is situated Longitude $07^{\circ} 00^{\prime} 45^{\prime \prime} \mathrm{E}$ and Latitude $04^{\circ} 46^{\prime} 41^{\prime \prime} \mathrm{N}$. Port Harcourt local government area is bounded in the southern by Okrika LGA and in the eastern by Eleme LGA and in the northern by Obio/Akpor LGA and in the western by Degema. The land total area is 109 square kilometers, and population size of 631,972 according to census 2006, NPC Port Harcourt office. It has neighbourhoods like D-line borokiri, diobu, old Port Harcourt, old GRA, and new GRA, Port Harcourt. The mayor serves as the chairman and heads the city council and is made up of 20 wards (electoral) as part of the Rivers east senatorial area.

The tropical monsoon climate is characterized by heavy rainfall from April to October ranging from 2000 to $2500 \mathrm{~mm}$ with high temperature all the year round and a relatively constant high humidity (Eludoyin et al, 2011). The vegetation found in this area includes raffia palms, thick mangrove forest and light rain forest (Eludoyin et al, 2011).

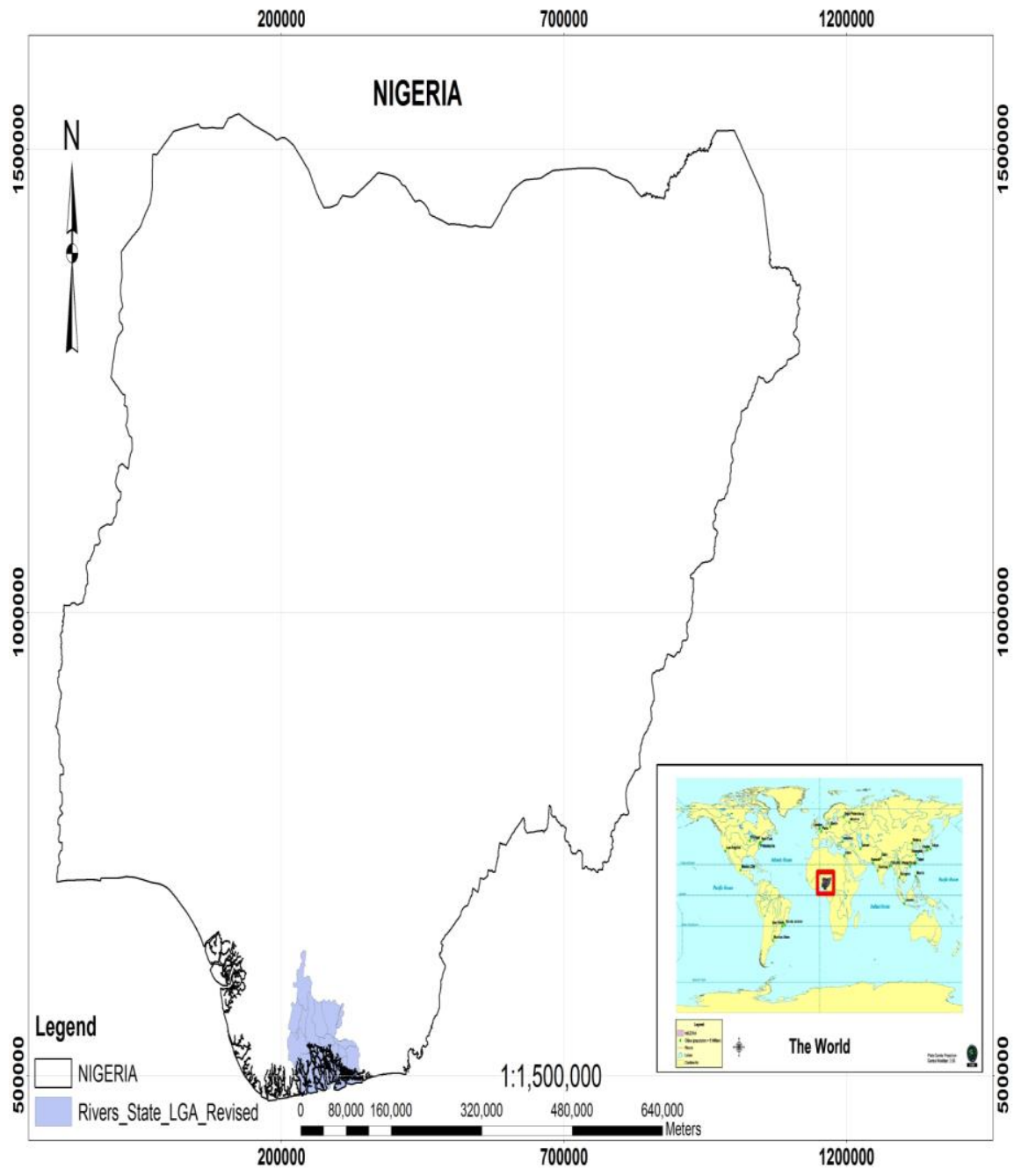

Fig. 1: Map of Nigeria Showing Rivers State. 


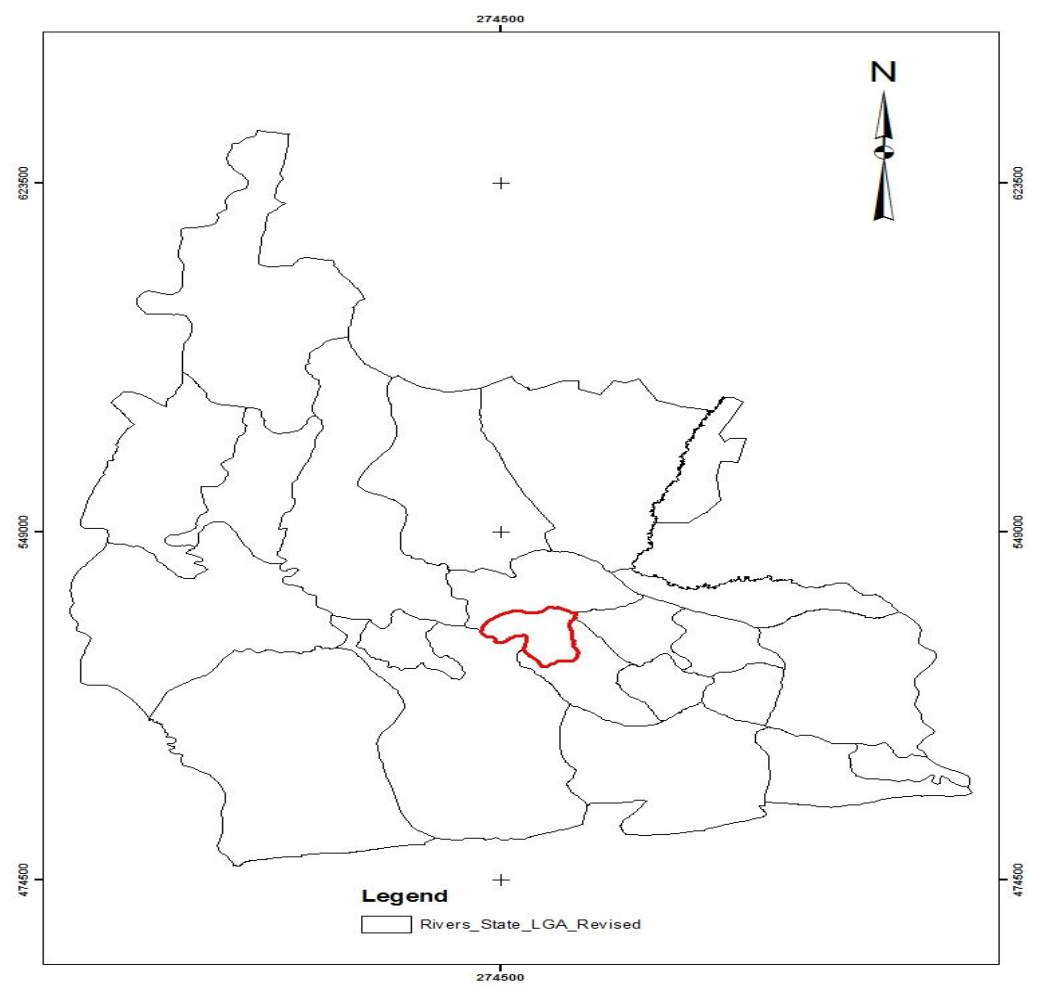

Fig. 2: Map of Rivers State Showing the Study Area.

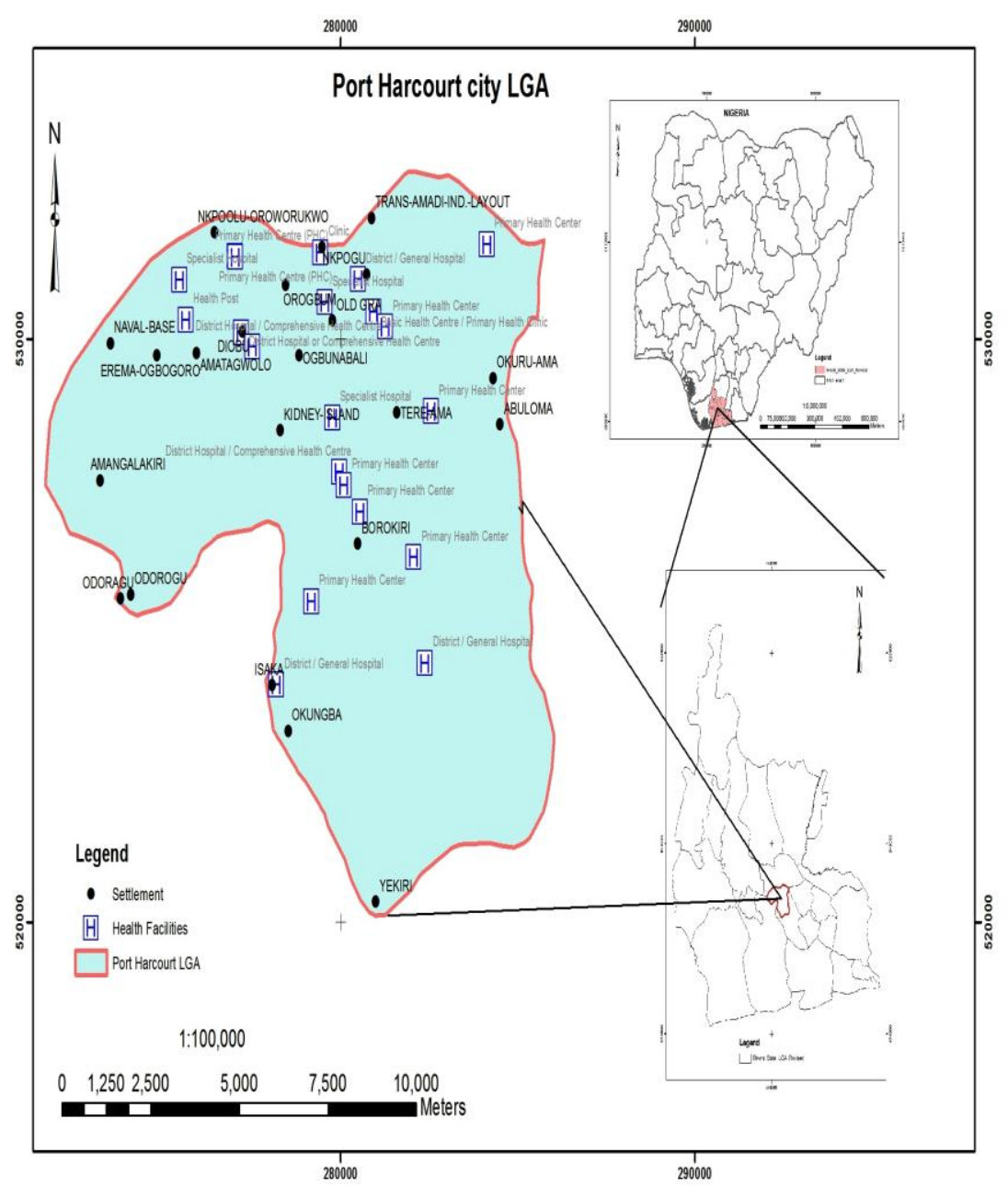

Fig. 3: Map Showing the Study Area. 


\section{Methodology}

\subsection{GIS operation concept used}

Symbols: geographical entity or phenomena relating to position or location are represented on a map as symbols. These entities or phenomena are model as point, line, area, and volume. Symbols are mostly used to represent attribute's data.

Overlay operation: Overlay operations are carried out on vector and raster by the use of relational operators, arithmetic, and boolean.

Buffer: Buffer as a tool is used to define or identify an area around or within a distance limit of facility or feature. Overlapping buffers indicate an area under services area. Buffer Tools are useful as an access indicator in a particular situation.

\subsection{Data sources and collection}

The primary and secondary data were used in this work. Primary data was captured using a Garmin Map 60CSX GPS handheld receiver. The GPS recreational receiver was used to capture the geographic location (coordinates) of health facilities or hospital and other data. Secondary data include population data, administrative map, road, settlement and names of hospitals. The administrative map and roads' data set was in Esri shape from the ministry of lands and survey Rivers State and geo referenced to WGS 1984 UTM Zone $32 \mathrm{~N}$.

\subsection{Methods}

The existing roads, settlements and administrative map were collected from the ministry of lands and survey, Rivers State in a digital dwg file format converted to Esri shape file format using interoperability function and matched to study area. The shape files overlay and matched on Google's earth imagery using Google's earth professional edition. The digital roads were converted to network data set using ArcGIS 10 .0. GPS point coordinates of health facilities converted to Esri shape file format using interoperability extension from GPS file format into the point map with attributes.

Furthermore, attribute query carried out to determine number of facilities and there categories.

Buffer analysis carried out to determine service area. Kernel density will be to determine population density within the study area.

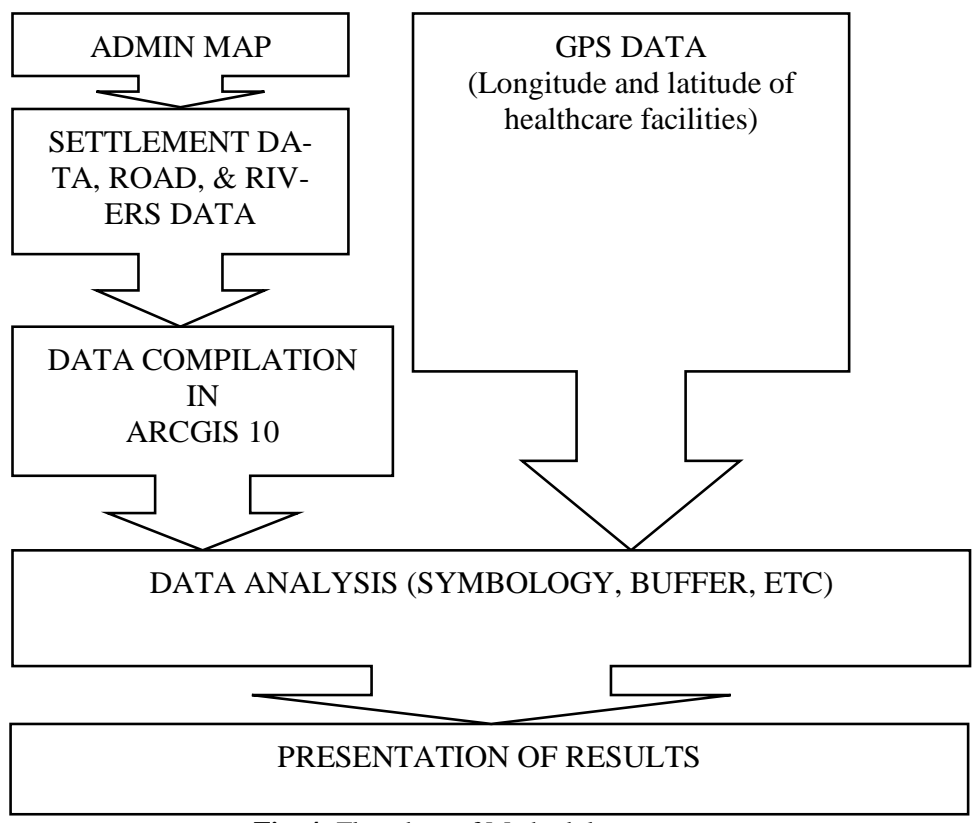

Fig. 4: Flowchart of Methodology.

\section{Results and discussion}

Research result as in (Fig 3) shows the geographical distribution of health facilities in Port Harcourt city council towns. It results reveal three (3) specialist hospital, three (3) general hospital, three
(3) Hospital Health Centre, eight (8) Primary Health Centre, and one (1) Health local Post. Most of the health facilities public owned. This implies that majority are owned by government, although individuals and cooperate organization have been contributing to health facilities development. 


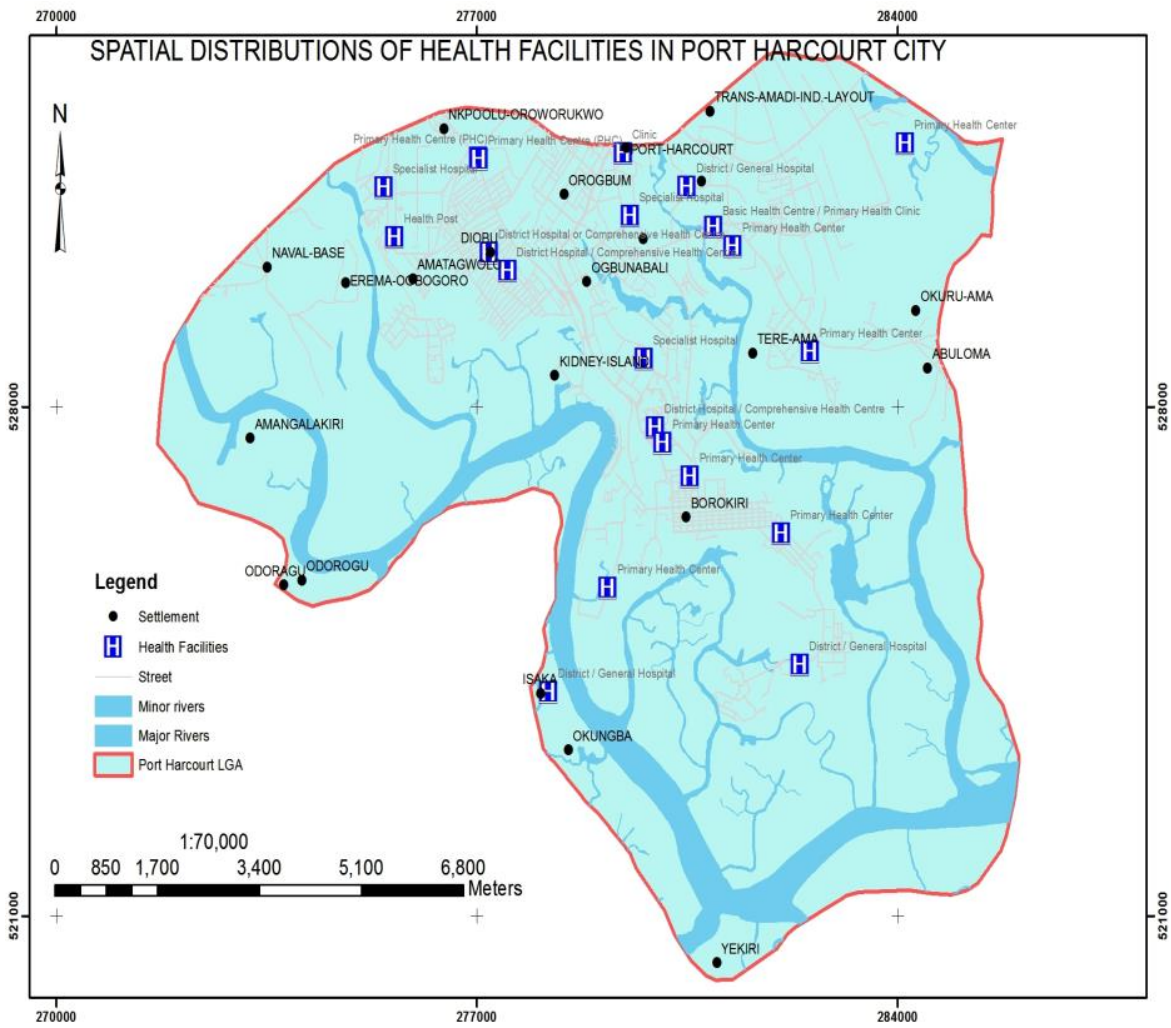

Fig. 5: Map Showing Health Facilities Distributions in Port Harcourt City LGA.

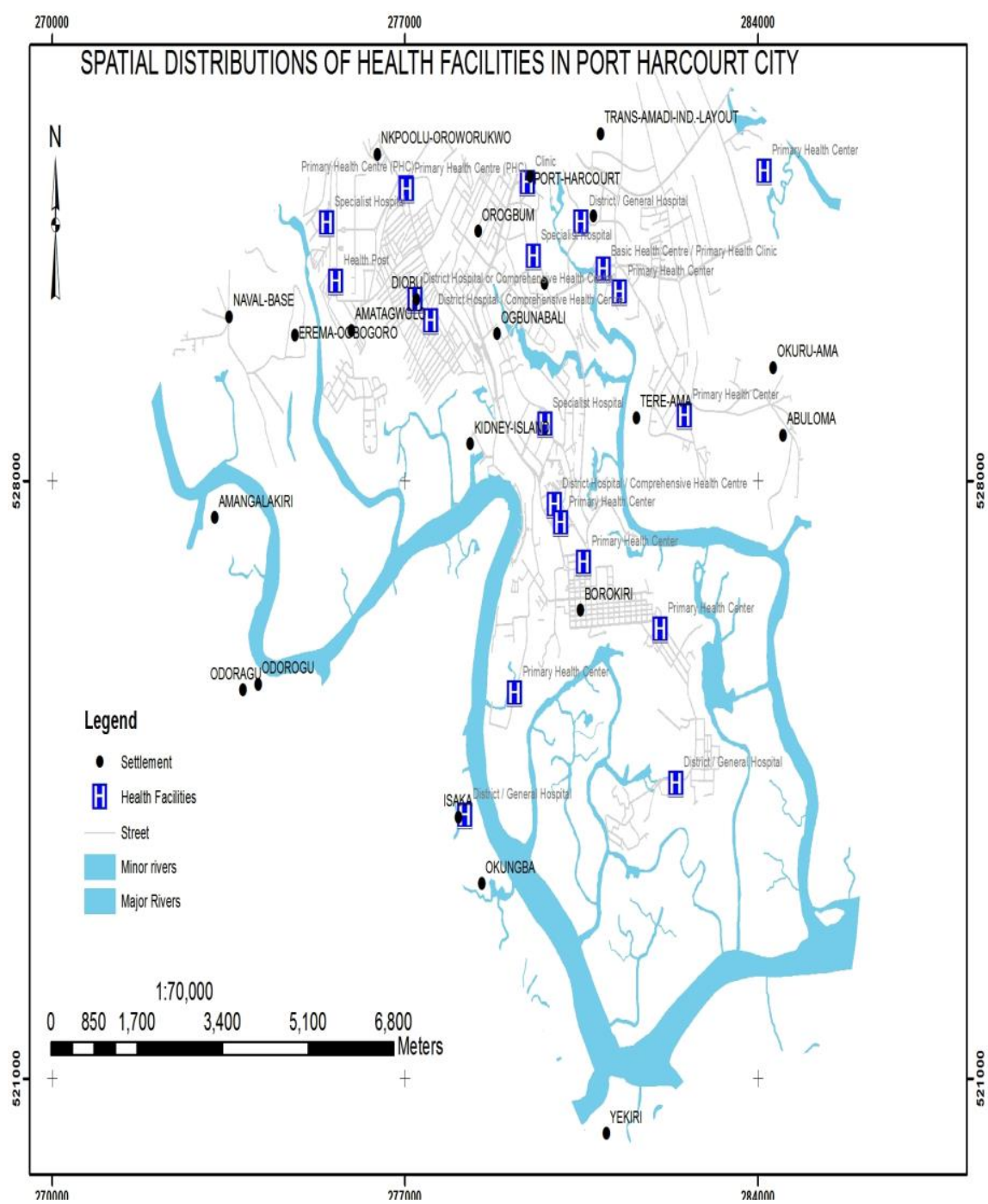

Fig. 7: Spatial Distributions Health Facilities in Port Harcourt City LGA. 


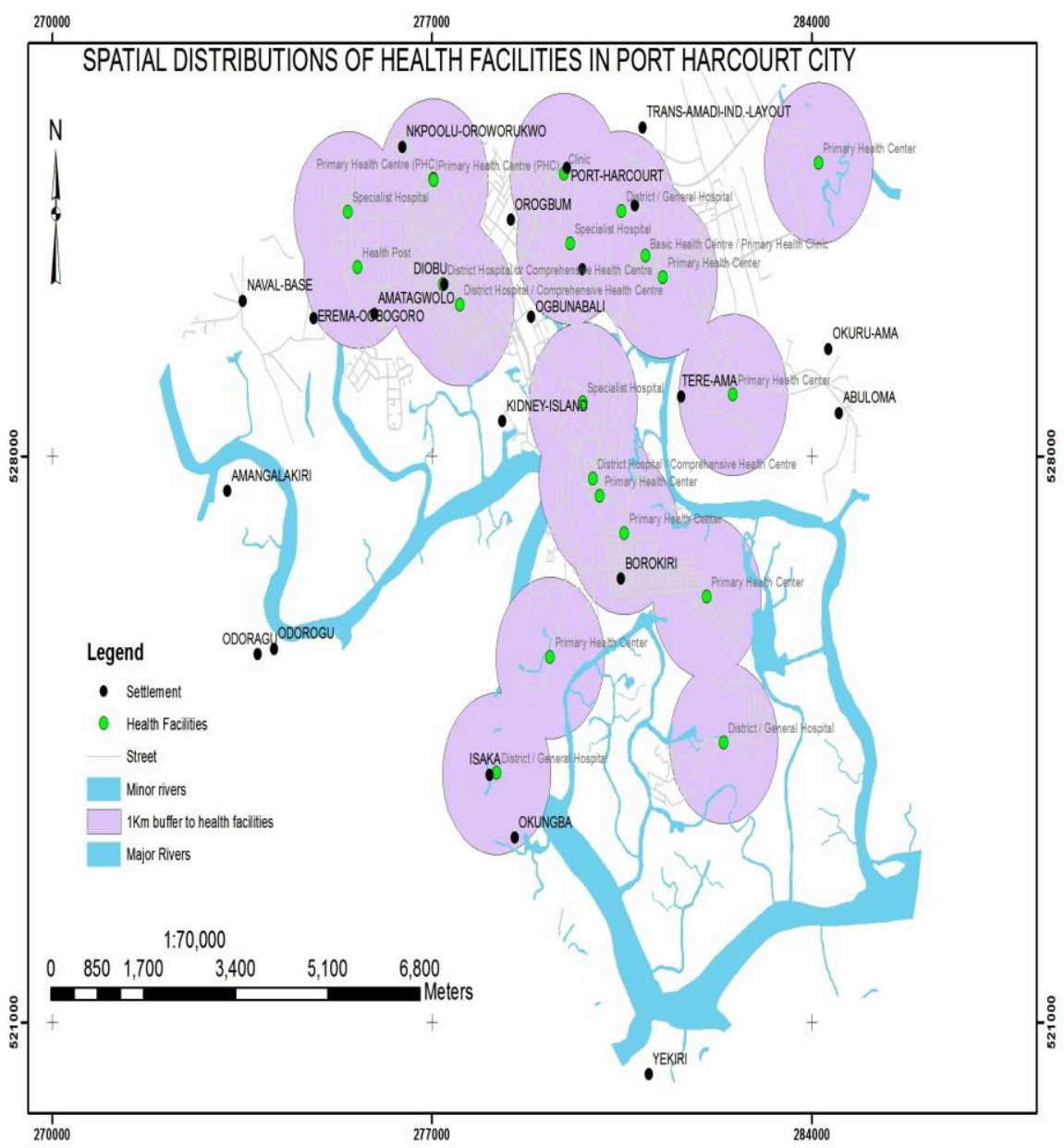

Fig. 6: Health Facilities $1 \mathrm{~km}$ Service Area in Port Harcourt City LGA.

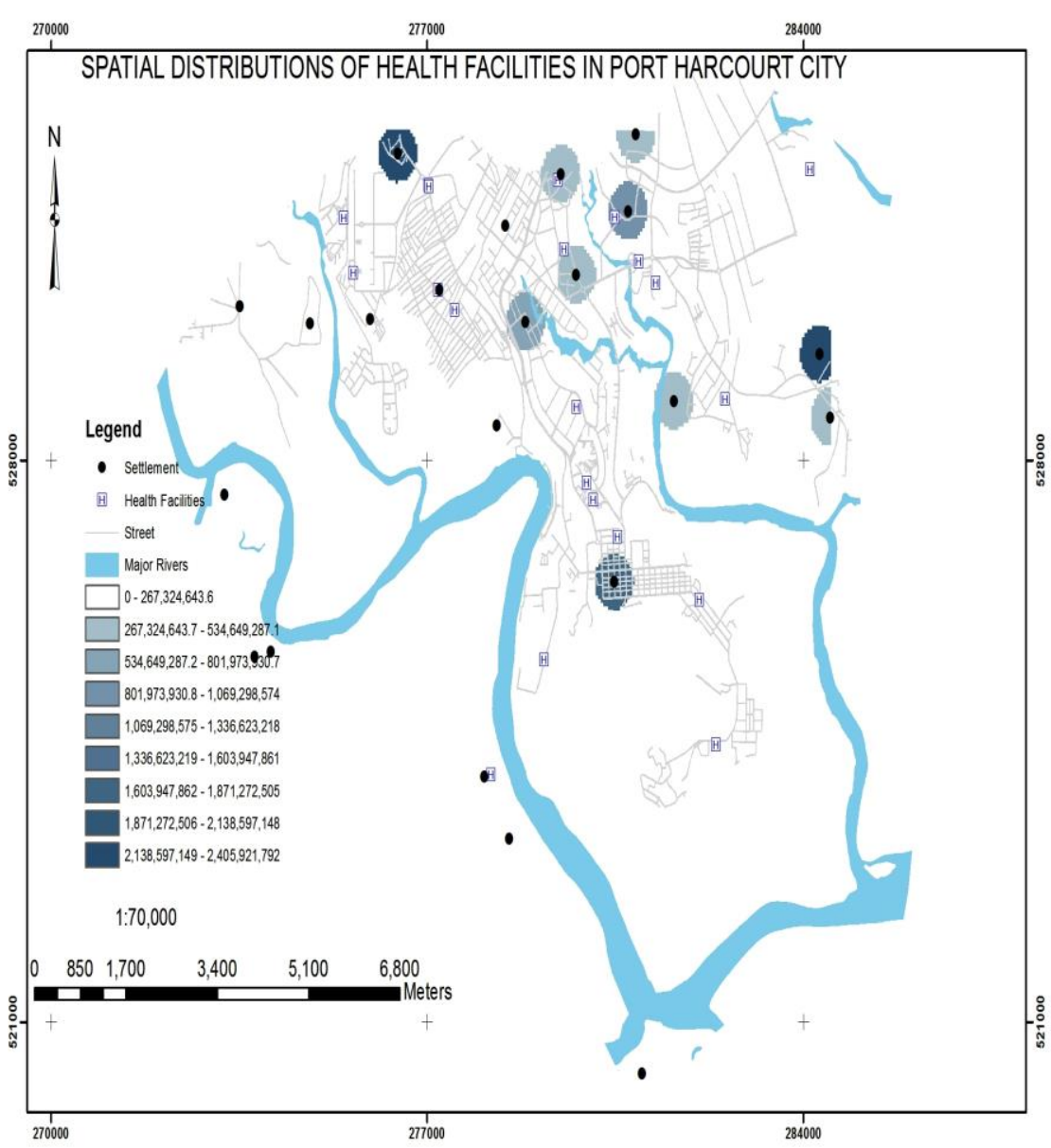

Fig. 8: Population Density (Kernel) Distributions in Port Harcourt City LGA. 


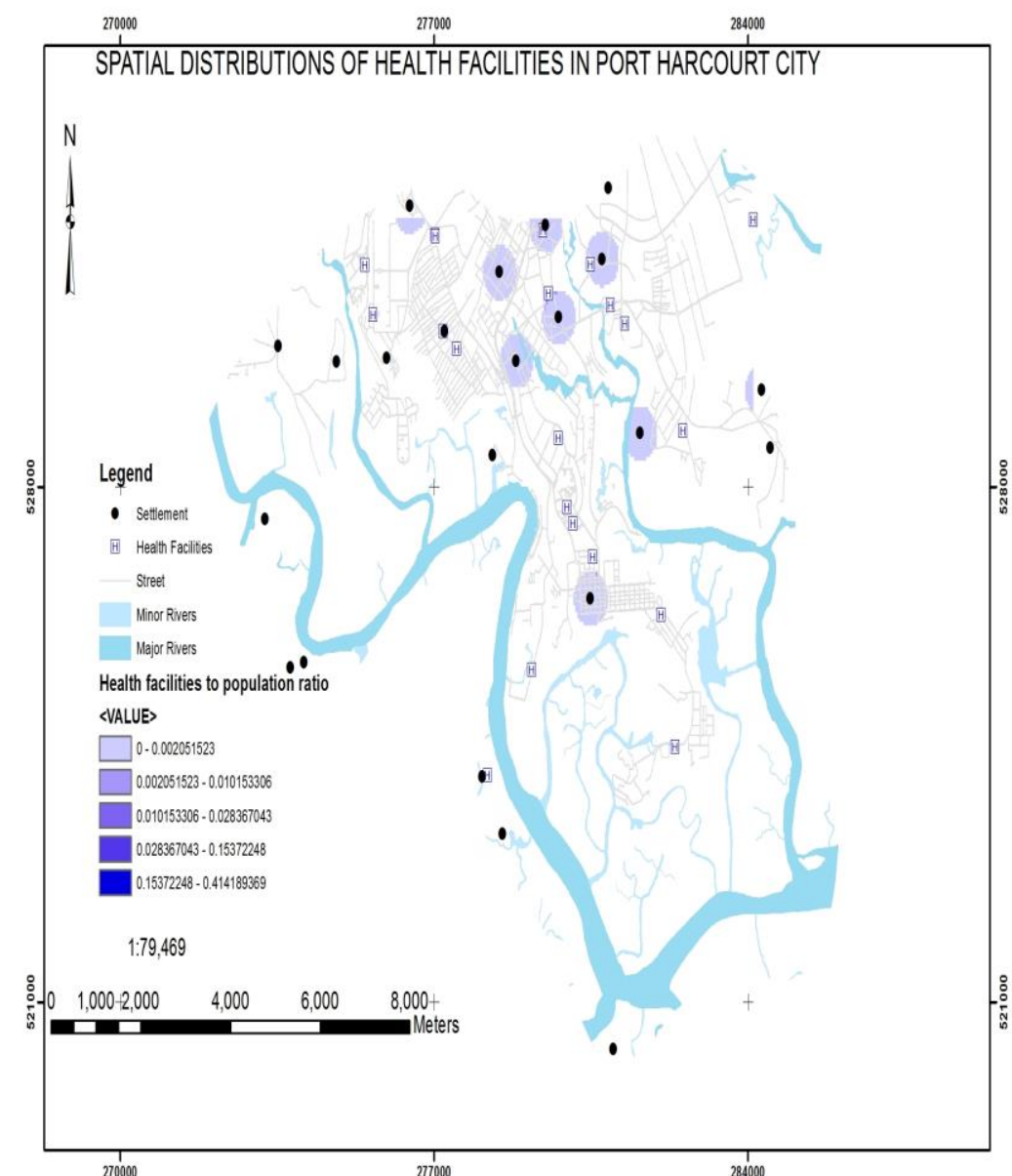

Fig. 9: Health Facilities to Population Density Ratio Distributions in Port Harcourt City LGA.

\section{Conclusion and outlook}

Spatial assessment of health facility's distributions in health systems is important, especially in emergencies. Although the quality of the assessments here is not complete for a health system, in sight's gain suggests that health facility's data can be collected and manage using GIS.

Furthermore, GIS is needed as essential criteria for data collection and to establish health systems and member of assessment experts to be deployed during future emergencies. Future work contains the solution for disease spread over the number of healthcare facilities and the professional personnel ratio to the specific standard.

\section{Acknowledgement}

I thank the formal Surveyor-General of Rivers State, Surveyor Gaius Assor and Surv. Peter Ogolo for the administrative map, settlement data, road data and rivers of River's state used for this research.

\section{References}

[1] E Abbas, I. I., Abdulqadir, H. Z., \& Bello, M. N., (2014), Mapping the Spatial Distribution of Health Care Facilities of the Millennium Development Goals (MDGs) in Kaduna North and South. Global Journal of HUMAN-SOCIALSCIENCE: B Geography,GeoSciences,Environmental Disaster Management. Volume 14 Issue5 Version1 $\quad \mathrm{p} \quad 1-12 \quad$ Available: http://socialscienceresearch.org/index.php/GJHSS/article/viewFile/ $1036 / 981$

[2] Abdurrahman B. I., Nurünnisa U., (2013).A GIS-based Spatial Analysis of Health care Facilities in Yola, Nigeria. GEOProcessing 2013: The Fifth International Conference on Advanced Geographic Information Systems, Applications, and Services. P46-52
[3] David J. B. (1997). GIS Primer. Pacific Meridian Resources, Inc.

[4] Egwu, I. N. (1996). Primary Health Care System in Nigeria: Theory, Practice and Perspectives. Lagos: Elmore Printing \& Publishing Co.

[5] Eludoyin O.S. Wokocha C.C. and Ayolagha G. (2011). GIS Assessment of Land Use and Land Cover Changes in Obio/Akpor L.G.A., Rivers State, Nigeria. Research Journal of Environmental and Earth Sciences, 3(4), 307-313. Retrieved May 21, 2016, from http://maxwellsci.com/print/rjees/v3-307-313.pdf

[6] Fanan U, Felix K., (2014). Spatial distributions of health facilities in Benue State.Journal Public Health Research. 4(5): 210218.doi:10.5923/j.phr.20140405.09

[7] FMH. (2009). the National Strategic Health Development Plan Framework (2009-2015). Federal Ministry of Health, Nigeria. Abuja: internationa lhealth partnership. Retrieved July 20, 2016, from http://www.internationalhealthpartnership.net/fileadmin/uploads/ih p/Documents/Country_Pages/Nigeria/Nigeria\%20National\%20Strat egic

[8] Shaikh, M.A. (2013). Spatial distributions of health facilities in Islamabad, Pakistan. EMHJ - Eastern Mediterranean Health Journal, 19 (Supp.2), 1-4, 2013. Available: http://apps.who.int/iris/handle/10665/118611. Accessed 20 june, 2016.

[9] WHO. (2004). A glossary of terms for community health care and services for older persons. WHO. Retrieved May 29, 2016, from http://www.who.int/kobe_centre/ageing/ahp_vol5_glossary.pdf. 